\title{
Severe tooth wear in Prader-Willi syndrome. A case-control study
}

\author{
Ronnaug Saeves ${ }^{1 *}$, Ivar Espelid ${ }^{2}$, Kari Storhaug $^{1}$, Leiv Sandvik ${ }^{2}$ and Hilde Nordgarden ${ }^{1}$
}

\begin{abstract}
Background: Prader-Willi syndrome (PWS) is a rare complex multsystemic genetic disorder characterized by severe neonatal hypotonia, endocrine disturbances, hyperphagia and obesity, mild mental retardation, learning disabilities, facial dysmorphology and oral abnormalities. The purpose of the present study was to explore the prevalence of tooth wear and possible risk factors in individuals with Prader-Willi syndrome.
\end{abstract}

Methods: Forty-nine individuals (6-40 years) with PWS and an age- and sex-matched control group were included. Tooth wear was evaluated from dental casts and intraoral photographs and rated by four examiners using the Visual Erosion Dental Examination (VEDE) scoring system and the individual tooth wear index $I_{A}$. In accordance with the VEDE scoring system, tooth wear was also evaluated clinically. Whole saliva was collected.

Results: Mean VEDE score was $1.70 \pm 1.44$ in the PWS group and $0.46 \pm 0.36$ in the control group $(p<0.001)$. Median I $I_{A}$ was 7.50 (2.60-30.70) in the PWS group and $2.60(0.90-4.70)$ among controls $(p<0.001)$. In the PWS group tooth wear correlated significantly with age (VEDE; $\left.r=0.79, p<0.001, I_{A} ; r=0.82, p<0.001\right)$ and saliva secretion (VEDE; $r=0.46, p=0.001, I_{A} ; r=0.43, p=0.002$ ). Tooth grinding was also associated with tooth wear in the PWS group, as indicated by the mean VEDE $2.67 \pm 1.62$ in grinders and $1.14 \pm 0.97$ in non-grinders $(p=0.001)$ and median $I_{A}$ values $25.70(5.48-68.55)$ in grinders and $5.70(1.60-9.10)$ in non-grinders $(p=0.003)$. Multivariate linear regression analysis was performed with tooth wear as the dependent variable and PWS (yes/no), age, tooth grinding and saliva secretion as independent variables. PWS (yes/no), age and tooth grinding retained a significant association with tooth wear, VEDE $(p<0.001)$ and $\log I_{A}(p<0.001)$. The only factor significantly associated with tooth wear in the control group was age.

Conclusions: Our study provides evidence that tooth wear, in terms of both erosion and attrition, is a severe problem in Prader-Willi syndrome. There is therefore considerable need for prosthodontic rehabilitation in young adults with PWS.

Keywords: Prader-Willi syndrome, Tooth wear, Tooth grinding, Saliva secretion, Rehabilitation

\section{Background}

Prader-Willi syndrome (PWS) is the most common genetic human obesity syndrome. Recent epidemiological surveys estimate birth incidence to be at least 1:30000 and population prevalence up to 1:52000 [1-4]. The syndrome affects both males and females equally [1,5-7]. PWS is a complex multi-system disorder arising from lack of expression of paternally inherited genes on chromosome 15q11-q13 [7-11]. PWS develops if the paternal

\footnotetext{
* Correspondence: Ronnaug.Saeves@tako.no

${ }^{1}$ TAKO-centre, Lovisenberg Diakonale Hospital, Lovisenberggt 17, 0440 Oslo, Norway

Full list of author information is available at the end of the article
}

alleles are defective, missing or silenced. There is paternal deletion of chromosome 15q11-q13 in 70\% of cases, maternal uniparental disomy (UPD) in $25 \%$, and imprinting defects in $1 \%$ of cases $[7,12,13]$.

The syndrome has a characteristic phenotype $[14,15]$ which includes neonatal and infantile hypotonia, early feeding problems (naso-gastric tube feeding for more than two months), childhood onset hyperphagia, obesity, short stature associated with growth hormone (GH) deficiency, high pain threshold, learning disabilities and behavioral problems. Excessive daytime sleepiness and sleep apnea are common in individuals with PWS [16-18]. A narrow forehead, almond-shaped eyes, downturned corners of the mouth and a thin upper lip are

\section{Biomed Central}


characteristic facial features. Varying degrees of oral motor dysfunction is common in individuals with PWS [19].

Thick, viscous saliva has been reported to be a consistent finding in PWS [20-22] and a diagnostic indicator of PWS in neonates [23]. Decreased salivary flow rates [24] and increased amounts of salivary ions and proteins have also been reported [20,21]. Dental caries [25-28], enamel defects [27-31] and poor oral hygiene [27,28] have been described in case reports. However, compared with previous reports, recent studies have identified more favourable oral health with respect to caries experience $[22,24]$.

Progressive dental tissue loss (tooth wear) has been reported in PWS [22,32] and gastro-oesophageal reflux described in one case report [27]. To our knowledge, no studies on tooth wear in a PWS population compared with a control group have been published.

The present study is part of a comprehensive survey. The aim of this study was to explore the prevalence of tooth wear and associated risk factors in individuals with Prader-Willi syndrome. The null hypothesis predicted no difference in prevalence of tooth wear between individuals in the PWS group and an age- and sex matched control group.

\section{Methods}

The study was carried out at the TAKO-centre, Lovisenberg Diakonale Hospital and at the Faculty of Dentistry, University of Oslo. The TAKO-centre is a national resource centre for oral health in rare medical conditions (frequency of less than 1:10 000). This study used an observational, matched case-control design.

\section{Ethical approval}

The study protocol was approved by the Regional Committee for Medical Research Ethics and The Norwegian Data Inspectorate. Informed consent was obtained from all participants. When participants were under 18 years of age or were adults with a guardian, informed consent was also obtained from the parents or guardian.

\section{Study participants}

Participants were recruited through the Norwegian Prader-Willi syndrome association. All association members aged 5 years and older $(n=95)$ received written information, designed for both children and adults, describing the study. Fifty-four individuals with PWS responded. Two of those who initially agreed to participate, later changed their minds due to the long travelling distance to the clinic. Two individuals were excluded after undergoing a new genetic test (negative Multiplex Ligation-dependent Probe Amplification), whilst one participant had only primary teeth and was therefore excluded from this part of the study. The final study group comprised 49 individuals (24 F, $25 \mathrm{M}$ ), age range 6.5-40.9 years. The examinations took place between January 2007 and April 2009. Confirmation of the genetic diagnosis of PWS was obtained from 3 different medical genetic centres. The participants came from all over Norway, although five children (6-13 years) in the study group were not ethnic Norwegians, as their parents came from Africa, Asia and Eastern Europe.

The control group was age- and sex-matched to the PWS group. Twenty-three healthy, unmedicated control participants (age 6-18 years) were recruited among patients at the Department of Pediatric Dentistry, Faculty of Dentistry, University of Oslo and 26 healthy adults were recruited among the staff at the Lovisenberg Diakonale Hospital. None of the control persons were dental personnel, and they were not expected to have more knowledge of dental health than the general population. All individuals with PWS and 26 of the controls were examined at the TAKO-centre, while the remaining 23 controls (6-18 years) were examined at the Department of Pediatric Dentistry, University of Oslo.

\section{Questionnaires}

All participants with PWS underwent a thorough, structured anamnestic interview either during the consultation or, if parents did not attend the consultation, by telephone. The interview focused on oral and general health, sleep disorders, gastric reflux, medications (e.g. use of growth hormone) and nutrition. The frequency of consumption of acidic food and drinks was categorized as follows: More than once daily; once daily; several times per week; once per week; or never. Information about tooth grinding was also obtained. A modified questionnaire, omitting questions not relevant for a healthy control group, was given to the control group prior to the examination. Dental records, including radiographs, from all study participants and controls under 19 years of age, were recovered from the public dental health service where all individuals under the age of 19 years and all with mental retardation regardless of age receive free dental care.

\section{Clinical assessments}

Prior to the examination, all participants (and/or their carers) received written information and photographs describing the procedures. Study participants and controls were examined once by the same examiner (RS). Intraoral photographs were taken of all participants and dental impressions (alginate) were taken of 48 participants from each group. Dental impressions were not taken of two individuals due to cooperation problems (PWS, $\mathrm{n}=1$ ) or ongoing orthodontic treatment with fixed appliances (control, $\mathrm{n}=1$ ). 
Tooth wear was evaluated using two indices, the Visual Erosion Dental Examination (VEDE) scoring system [33] and a modified individual tooth wear index $\left(\mathrm{I}_{\mathrm{A}}\right)$ [34]. In the study group tooth wear was evaluated clinically by RS according to the VEDE scoring system. The VEDEindex, a modification of the dental erosion index proposed by Lussi [35], is a 6-point scoring system which contains a visual guide with clinical photos: $0=$ no erosive wear; $1=$ loss of enamel surface characteristics; $2=$ loss of enamel surface contour; $3=$ loss of dentine from less than one-third of the surface; $4=$ loss of dentine from more than one-third and less than twothirds of the surface; $5=$ loss of dentine from more than two-thirds of the surface. Tooth wear was evaluated for each permanent tooth surface (buccal/labial, occlusal/ incisal and palatinal/lingual), using compressed air to dry the teeth, cotton rolls to remove debris where necessary, a dental mirror, probe and optimal light. The observations were dictated to a dental nurse who recorded the scores in a diagram. An individual mean VEDE-score was calculated by summing up the highest surface score for each tooth divided by the number of teeth present. This was used in the data analyses.

Before using the VEDE scoring system, calibration using 74 surfaces from intraoral close-up photographs in a training program [33] was performed by four examiners. Interobserver agreement was 0.68 expressed as linear weighted Cohen's kappa $\left(\mathrm{K}_{\mathrm{w}}\right)$ [36]. To further test the reliability of the principal observer the same observers scored intraoral photos and dental casts using the VEDE-index [33] on non-occluding surfaces (of all study participants, from distal surface of upper right canine tooth to distal surface of upper left canine tooth) (Table 1). Interexaminer agreement $\left(\mathrm{K}_{\mathrm{w}}\right)$ in the evaluations of VEDE was 0.51 . The scores by RS were close to the mean of the four examiners.

Tooth wear on occluding surfaces was evaluated by four examiners on dental casts and intraoral photographs using the $\mathrm{I}_{\mathrm{A}}$ index. This index recorded tooth wear on a 4-point scale: $0=$ no or minimal wear; $1=$ wear of enamel down to dentine spots; 2 = wear of the dentine down to one-third of the crown height; 3 =wear of the dentine greater than one-third of crown height. In this study, the

Table 1 Tooth wear presented as mean VEDE by four examiners

\begin{tabular}{lll}
\hline \multirow{2}{*}{ Examiners } & \multicolumn{2}{l}{ VEDE $^{\mathbf{a}}$} \\
\cline { 2 - 3 } & PWS & Control \\
\hline$I$ & $1.50( \pm 1.5)$ & $0.48( \pm 0.7)$ \\
\hline$I I$ & $0.57( \pm 1.0)$ & $0.12( \pm 0.3)$ \\
\hline RS & $1.14( \pm 1.1)$ & $0.38( \pm 0.5)$ \\
\hline${ }^{a}$ Mean (standard deviation). & $1.15( \pm 1.1)$ & $0.18( \pm 0.3)$ \\
\hline
\end{tabular}

presence of a dental prosthetic crown due to tooth wear (according to the dental records) also qualified for a score of 3 . The individual tooth wear index $\left(\mathrm{I}_{\mathrm{A}}\right)$ was calculated using the following formula: $\left(10 G_{1}+30 G_{2}+100\right.$ $\left.G_{3}\right) /\left(G_{0}+G_{1}+G_{2}+G_{3}\right)$, where $G_{0}, G_{1}, G_{2}$ and $G_{3}=$ number of teeth with occlusal wear scores of $0,1,2$ and 3 respectively [34]. Before evaluating tooth wear, the examiners were calibrated and blinded examinations were performed. The mean score from the four examiners was used to calculate the severity of incisal and occlusal wear $\left(\mathrm{I}_{\mathrm{A}}\right)$. Interexaminer agreement $\left(K_{w}\right)$ in the evaluations of $I_{A}$ was 0.67 . The modified $\mathrm{I}_{\mathrm{A}}$ was logarithmically transformed to render a more symmetrical distribution of data in regression analyses.

Unstimulated whole saliva (UWS) was collected and salivary volumes determined by weight $(1 \mathrm{~g}=1 \mathrm{ml})$. The flow rates are presented as $\mathrm{ml} / \mathrm{min}$. Results of the saliva analyses have been presented elsewhere [24]. However, as this information may be relevant for tooth wear, the UWS values were included in the present analyses. BMI calculated on the basis of measured height and weight, was age- and gender adjusted [37] and is presented elsewhere [24]. Three participants from the study group who had extensive tooth wear and cooperated well with the examination procedures, were referred to 24-h oesophageal pH-metry.

\section{Statistical analysis}

The interexaminer agreement was measured using linear weighted Cohen's kappa. Calculations were based on raw data. A two-sided $t$-test was used to compare VEDE between the two groups, whilst a two-sided Mann-Whitney test was used to compare $\mathrm{I}_{\mathrm{A}}$. The association between two continuous variables: tooth wear and age, and tooth wear and saliva secretion was analysed by Spearman correlation coefficient (r). To study the relationship between tooth wear $\left(\mathrm{VEDE}\right.$ and $\left.\log \mathrm{I}_{\mathrm{A}}\right)$ and several variables simultaneously, linear regression analysis was performed. The following variables were significantly associated with tooth wear and became candidates for multivariate analysis; PWS (yes/no), age, tooth grinding (yes/no), and saliva secretion. A significance level of 5\% was used throughout. The statistical analysis was carried out using the statistical software program SPSS $\odot$ (v. 18.0, SPSS Inc., Chicago, III., USA).

\section{Results}

Characteristics of the study population are presented in Table 2. Eighteen individuals with PWS and 3 controls reported tooth grinding. The number of individuals reporting high consumption of acidic food and drinks was much higher among individuals with PWS than in controls (Table 3). Twelve out of forty-nine individuals with PWS reported that they did not like and did not 
Table 2 Characteristics of the study population

\begin{tabular}{lll}
\hline & $\begin{array}{l}\text { PWS group } \\
(\mathbf{n}=\mathbf{4 9 )}\end{array}$ & $\begin{array}{l}\text { Control } \\
\text { group }(\mathbf{n}=\mathbf{4 9})\end{array}$ \\
\hline Age range (years) & $6.5-40.9$ & $6.1-42.5$ \\
\hline Mean age \pm s.d. & $20.4 \pm 9.5$ & $20.8 \pm 10.1$ \\
\hline Number of individuals & $\mathrm{n}$ & $\mathrm{n}$ \\
\hline Age group 6-18 years & 23 & 23 \\
\hline Age group 19-40 years & 26 & 26 \\
\hline Males/females & $25 / 24$ & $25 / 24$ \\
\hline
\end{tabular}

\begin{tabular}{lll}
\hline Supplementary diseases & & \\
\hline Diabetes & 3 & 0 \\
\hline Epilepsy & 3 & 0 \\
\hline Heart disease & 1 & 0 \\
\hline Daytime sleepiness or Sleep apnea & 20 & 0 \\
\hline
\end{tabular}

\section{BMI}

\begin{tabular}{lll}
\hline Normal weight & 14 & 49 \\
\hline Overweight & 17 & 0 \\
\hline Obese & 18 & 0 \\
\hline
\end{tabular}

\section{Medication}

${\text { Growth hormone }(\mathrm{GH})^{\text {a }}}{ }^{a} \quad 0$

BMI criteria were age- and gender adjusted for individuals 6-18 years according to International Obesity Task Force (IONT) (37).

${ }^{a}$ Duration of GH treatment ranged between 6 and 192 months. Mean duration was 72 months.

drink any water at all, whilst sixteen individuals drank some water as part of their fluid intake. Examples of extreme tooth wear are presented in Figure 1.

According to the VEDE-scoring system (clinical examination by RS), five individuals with PWS and seven controls did not have tooth wear. Mean VEDE score was $1.70 \pm 1.44$ in the PWS group and $0.46 \pm 0.36$ in the control group $(\mathrm{p}<0.001)$. Twenty-nine individuals with PWS and 13 controls presented with tooth wear exposing dentine (score 3, 4 and 5) or had dental crowns due to severe tooth wear. Tooth wear in three different age groups and according to mean VEDE-score is presented in Figure 2.

Table 3 Number of individuals with high consumption* of selected acidic drinks and foods

\begin{tabular}{llll}
\hline & $\begin{array}{l}\text { PWS } \\
(\mathbf{n}=\mathbf{4 9 )}\end{array}$ & $\begin{array}{l}\text { Controls } \\
(\mathbf{n}=\mathbf{4 9})\end{array}$ & p-value \\
\hline Drinks & & & \\
\hline $\begin{array}{l}\text { Sugared soft drinks carbonated/ } \\
\text { not carbonated }\end{array}$ & 1 & 4 & $0.17 \mathrm{~ns}$ \\
\hline $\begin{array}{l}\text { Diet soft drinks carbonated/ } \\
\text { not carbonated }\end{array}$ & 30 & 1 & $<0.001$ \\
\hline Natural fruit juice & 10 & 15 & $0.25 \mathrm{~ns}$ \\
\hline Foods & 36 & 27 & $0.06 \mathrm{~ns}$ \\
\hline Fruit & 16 & 7 & 0.03 \\
\hline Yoghurt & & & \\
\hline
\end{tabular}

"Combines the frequencies: 'daily' and 'several times a day'.
Four examiners evaluated tooth wear (presented as median $\mathrm{I}_{\mathrm{A}}$ ) from dental casts and intraoral photographs (Table 4). No tooth wear according to the $\mathrm{I}_{\mathrm{A}}$ index $\left(\mathrm{I}_{\mathrm{A}}=0\right)$ was recorded in four individuals with PWS and in six controls. Median $\mathrm{I}_{\mathrm{A}}$ was 7.50 (2.60-30.70) in the PWS group and $2.60(0.90-4.70)$ among controls $(\mathrm{p}<0.001)$. Median $\mathrm{I}_{\mathrm{A}}$ in three age groups is presented in Figure 3.

Mean unstimulated whole salivary flow rate in the PWS group was $0.12 \pm 0.11 \mathrm{ml} / \mathrm{min}$ as compared to $0.32 \pm 0.20 \mathrm{ml} / \mathrm{min}$ in the control group $(\mathrm{p}<0.001)$.

In the PWS group, tooth wear correlated significantly with age (VEDE; $\mathrm{r}=0.79, \mathrm{p}<0.001, \mathrm{I}_{\mathrm{A}} ; \mathrm{r}=0.82, \mathrm{p}<0.001$ ) and saliva secretion (VEDE; $\mathrm{r}=0.46, \mathrm{p}=0.001, \mathrm{I}_{\mathrm{A}} ; \mathrm{r}=0.43$, $\mathrm{p}=0.002)$. Comparing grinders and non-grinders mean VEDE was $2.67 \pm 1.62$ and $1.14 \pm 0.97, p=0.001$ respectively. Corresponding median $\mathrm{I}_{\mathrm{A}}$ values were 25.70 (5.48-68.55) vs. $5.70(1.60-9.10)(\mathrm{p}=0.003)$. No significant association was found between tooth wear and obesity, gender or self-reported consumption of acidic drinks in the PWS group. The only factor associated with tooth wear in the control group was age (VEDE; $\left.\mathrm{r}=0.77, \mathrm{p}<0.001, \mathrm{I}_{\mathrm{A}} ; \mathrm{r}=0.71, \mathrm{p}<0.001\right)$. The association between tooth wear and obesity or tooth grinding could not be evaluated in the control group, because there were no obese individuals and only 3 individuals reported tooth grinding. Multivariate linear regression analysis was performed with tooth wear as the dependent variable and PWS (yes/no), age, tooth grinding and saliva secretion as independent variables. PWS (yes/no), age and tooth grinding retained a significant association with $\operatorname{VEDE}(\mathrm{p}<0.001)$ and $\log \mathrm{I}_{\mathrm{A}}$ $(\mathrm{p}<0.001)$. The difference in mean VEDE between the PWS- and control group was 1.25 (CI 0.83-1.67) without adjustment, and 0.88 (CI $0.49-1.26$ ) when adjusting for age, tooth grinding and saliva secretion. Similarly, the difference in mean $\log \mathrm{I}_{\mathrm{A}}$ between the PWS- and control group was 1.04 (CI $0.60-1.48$ ) without adjustment and 0.69 (CI 0.32-1.06) when adjusting for age, tooth grinding and saliva secretion. The mean difference in VEDE score and median difference in $\mathrm{I}_{\mathrm{A}}$ score between the PWS and controls remained significant $(\mathrm{p}<0.001)$ when tooth grinders were excluded.

Clinical examination showed that six individuals in the PWS group had one or more dental crowns and three of them had all their teeth crowned due to tooth wear (according to previous dental records). The examination triggered referrals for prosthodontic treatment for 4 participants $(\mathrm{M} / 23, \mathrm{~F} / 24, \mathrm{M} / 28, \mathrm{M} / 36)$. Due to extreme tooth wear (some with pulp involvement), all teeth in these individuals were treated with dental crowns. No study participants or controls reported oral acid/burning sensation or a medical history of gastro-oesophageal reflux disease (GORD). Twenty-four-hour oesophageal pH-metry revealed severe pathological reflux in all three 

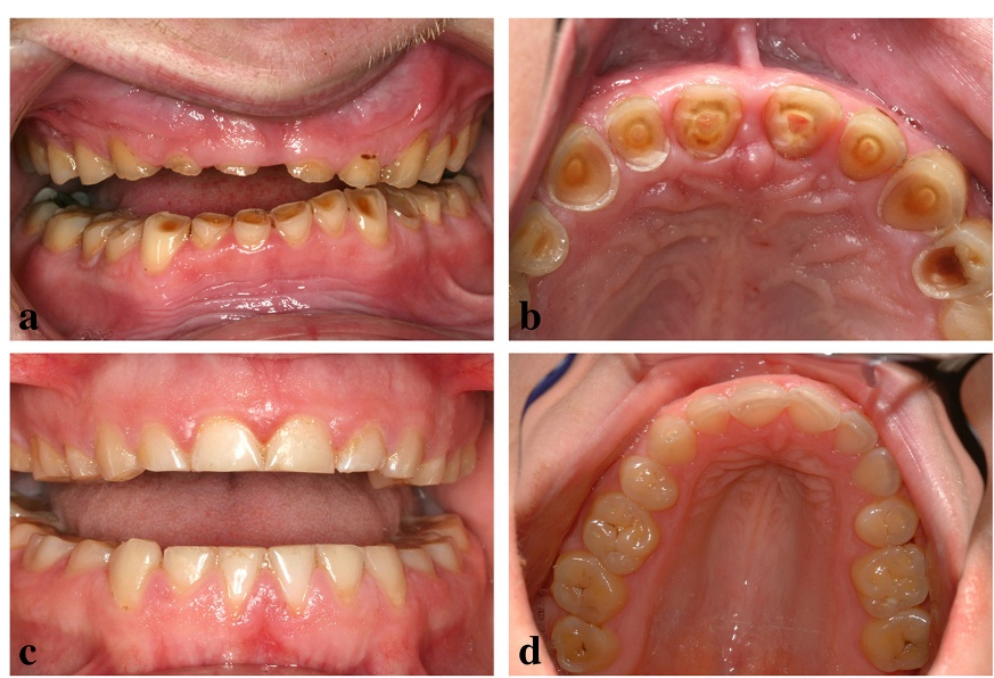

Figure 1 Tooth wear in PWS. (a, b) Extreme tooth wear with pulp exposure in 6 teeth in a 36-year-old male, (c, d) Typical tooth wear in a 28-year-old female.

individuals in the study group $(\mathrm{n}=2>18$ years, $\mathrm{n}=1<18$ years).

\section{Discussion}

To our knowledge this study is the first to evaluate tooth wear in Prader-Willi syndrome and compare it with a control group. Results from our study demonstrate extensive tooth wear in PWS compared with the control group, and the null hypothesis was therefore rejected. Tooth grinding was significantly associated with tooth wear and could explain it to some extent.

Tooth wear may be caused by either attrition, erosion, abrasion or a combination of these conditions. Reviewing the literature on tooth wear can be confusing as there

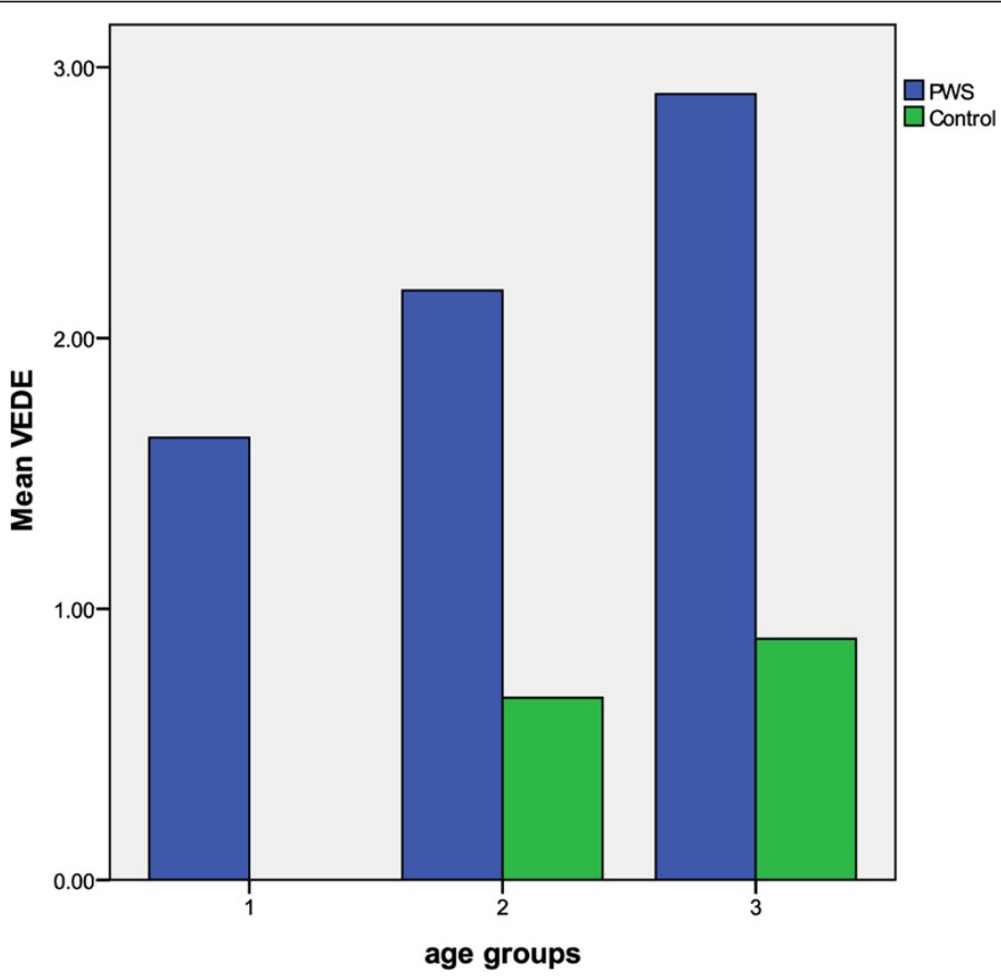

Figure 2 Tooth wear presented as mean VEDE for individuals in PWS- and control-group divided in three equally large age groups. Age groups (mean age, range years): 1; $9.8(6.1-13.6)(n=32), 2 ; 20.2(13.7-25.4)(n=34), 3 ; 31.5(25.5-42.5)(n=32)$. 
Table 4 Tooth wear presented as median $I_{A}$ by four examiners

\begin{tabular}{lll}
\hline \multirow{2}{*}{ Examiners } & \multicolumn{1}{l}{$\mathrm{I}_{\mathbf{A}}^{\mathrm{a}}$} & \\
\cline { 2 - 3 } & PWS & Control \\
\hline$I I$ & $10.40(3.8-48.0)$ & $4.40(1.3-6.9)$ \\
\hline $\mathrm{III}$ & $3.60(0.2-18.3)$ & $0.40(0-2.0)$ \\
\hline RS & $6.50(2.4-28.0)$ & $2.90(0.7-5.5)$ \\
\hline${ }^{a}$ Median (interquartile range). & $7.50(3.1-26.6)$ & $2.10(0.8-3.8)$ \\
\hline
\end{tabular}

seems to be lack of standardization of indices used in epidemiological studies on dental wear. No index seems to be ideal for use in epidemiological prevalence studies [38]. In the present study two indices have been used to focus on erosive wear (VEDE) as well as abrasion/attrition on occluding surfaces $\left(\mathrm{I}_{\mathrm{A}}\right)$. A large number of indices have been developed for diagnosing, grading and monitoring tooth wear. Some researchers have recorded lesions on an etiological basis (erosion indices) [39-42], whilst others have recorded lesions irrespective of etiology (tooth wear indices) [38,43]. Knowledge regarding the validity of current diagnostic criteria for different forms of tooth wear is incomplete and further research is needed [44]. The prevalence of tooth wear in healthy children and adolescents has been investigated using erosion indices in several studies $[40,45,46]$. Attrition is often considered to be the cause of wear of incisal and occlusal surfaces, although erosion may also be an important factor. The individual tooth wear index $\left(\mathrm{I}_{\mathrm{A}}\right)$ used in our study scores wear of both natural teeth and restorative materials, stating the ratio between the weighted sum of all teeth with some degree of tooth wear and the total number of teeth in that individual. The tooth wear may have been overestimated in individuals with PWS in this study as all teeth covered with dental crowns due to tooth wear were given a score of 3 (highest possible attrition score). Some of these teeth may have scored only 2 before treatment.

All study participants and controls were examined once by a single examiner (RS). Repeated clinical examinations (using two or more examiners) were not possible due to the significant travel distance to the clinic for many of participants. To counter this potential bias, 4 calibrated and blinded examiners evaluated tooth wear based on the VEDE- and $\mathrm{I}_{\mathrm{A}}$ indices using dental casts and intraoral photographs. The VEDE index is based on 6 categories whilst the $I_{A}$ index involves 4 . The low level of interexaminer agreement demonstrates reliability issues in the use of these scoring indices for erosive wear. This is in accordance with reports from other studies $[47,48]$. Due to the multifactorial causes of dental wear it is difficult for one examiner to establish the etiology in each case. Erosion and wear are related, but in occluding

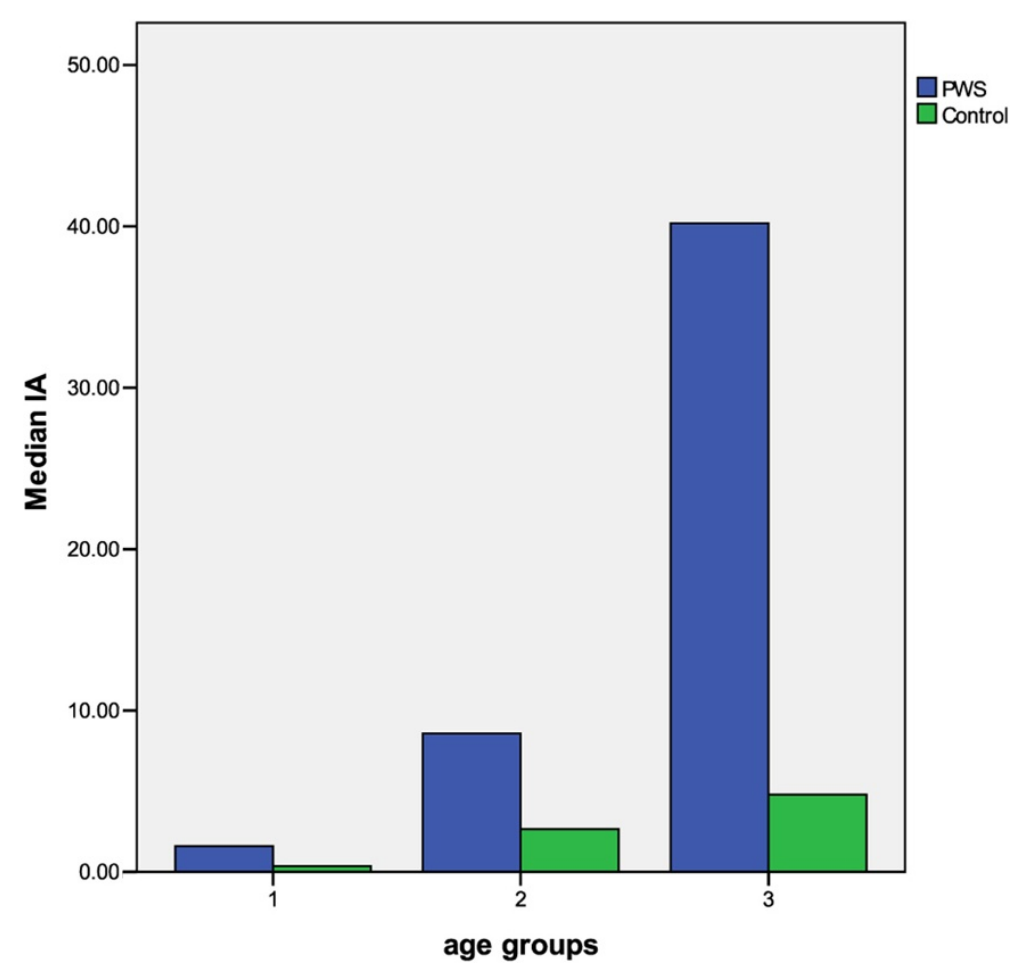

Figure 3 Tooth wear presented as median $\mathrm{I}_{\mathrm{A}}$ for individuals in PWS- and control-group divided in three equally large age groups. Age groups (mean age, range years): 1; $9.8(6.1-13.6)(n=32), 2 ; 20.2(13.7-25.4)(n=34), 3 ; 31.5(25.5-42.5)(n=32)$. 
surfaces the wear component might be considered as the main factor while erosion could be the most prominent cause of substance loss in non-occluding free surfaces. The two indices chosen, facilitates the monitoring of these aspects. The results showed consistently that individuals with PWS were more affected than the controls. In addition the principal examiner RS, was an average observer which indicate acceptable validity of the clinical recordings.

Moderate tooth wear may progress throughout life as part of normal aging. Few data are published describing levels of tooth wear according to age. Severe tooth wear has been reported to increase from $3 \%$ at the age of 20 to $17 \%$ at the age of 70 [49]. The occurrence of agerelated physiological tooth wear is controlled for in the present study as the PWS and control group are agematched.

Within the present study design the associations identified are not necessarily indicative of causality. However, several clinical findings may be of significance. Hyposalivation was found in 54\% of individuals in the PWS group and $3 \%$ in the control group [24]. Saliva protects the teeth against tooth wear $[32,50]$ as a result of its ability to form the acquired enamel pellicle which acts as a lubricant to reduce frictional wear. Also its buffering capacity, its clearance and dilution of acids in the mouth protect against enamel dissolution. In the PWS group tooth wear was associated with salivary flow rate. However, salivary flow rate did not maintain a significant association with tooth wear in the multivariate regression analysis. Hyposalivation could therefore be a minor factor contributing to the extreme tooth wear seen in individuals with PWS.

Unusual water intake and drinking behavior have been observed in people with PWS. Such behavior may reflect a hypothalamic alteration [51]. Most of the investigated study participants reported disliking water in infancy. Individuals with PWS, their parents and carers appeared to be well-informed on this issue, and described conscious efforts to teach their children to drink water from an early age.

Dental erosion is caused by the presence of intrinsic (gastro-oesophageal reflux) and/or extrinsic (most commonly dietary) acid of non-bacterial origin in the mouth [52]. Measurement of consumption of acidic food and drinks was based on self-report during the anamnestic interview, and information bias may therefore be a limitation in the present study. Data analysis revealed no statistically significant association between erosive wear and high consumption of acidic food and drinks. These results are in accordance with a study on a healthy population in Iceland [40]. Nevertheless, the role of dietary acids is considered to be the most common cause of erosive wear by many researchers $[41,42,53,54]$. The primary risk factor with dietary acids is high frequency of consumption. The dietary acids cause an immediate drop in oral $\mathrm{pH}$, which returns to physiological $\mathrm{pH}$ within a couple of minutes due to the neutralizing effect of saliva. Eating behaviors associated with PWS suggest that these individuals suffer from persistent hunger and a consequent urge to eat [55]. When they are given access to soft drinks it is therefore unlikely that drinking of the beverage is spread over time. This may go some way towards explaining the lack of association between high consumption of acid drinks and erosive wear.

In our study tooth grinding was recorded according to self-report or report by parents/carers. Given that the activity is thought to be cyclic and a parent or carer may not be in sufficiently close proximity to detect audible tooth grinding, some bruxing may be undetected, leading to underestimation of its true level. The frequency and intensity over time are seldom known. Reported tooth grinding varied significantly between the study group and control group. However, tooth grinding is unlikely to be the only cause of tooth wear as the significant difference between the two groups remained when tooth grinders were removed from the analysis. Similar findings have been reported by others $[34,56]$. The significance of tooth grinding as a causative factor is not fully known, but has probably been overestimated previously [57]. The multifactorial etiology of tooth grinding is wellrecognized. Potential contributors include psychological factors, sensitivity to stress, and arousals during sleep, with accompanying increases in heart rate, muscle activity, and physical movements [58,59]. The abnormal and frequent sleep arousals [60] and characteristic behaviors including self-harm and sensitivity to stress documented in PWS [61] may lead to tooth grinding as a sequela of the syndrome.

Gastro-oesophageal reflux (GORD) is an aspect of general health which may affect erosive wear. GORD is a significant intrinsic factor in dental erosion [42,62-64]. Studies have shown a significant increase in reflux symptoms in individuals with confirmed obstructive sleep apnea syndrome and increased BMI [65,66]. Central adiposity may be the most important risk factor for development of reflux [67]. In our study, 10 of 13 patients referred to polysomnography were diagnosed with obstructive sleep apnea syndrome and 37\% were obese with central obesity, both defined as risk factors in association with GORD. No study participants reported symptoms of reflux or heartburn, although all three examined individuals had severe reflux requiring medication. Symptoms of gastric reflux may be underreported because high pain threshold in PWS may lead to decreased recognition of injury or illness [7,68,69]. Alternatively individuals with the disorder may regard their long-standing reflux symptoms as "normal". The 
prevalence of GORD associated with extreme tooth wear in the three patients referred for reflux assessment suggests that GORD may be an etiological factor worthy of further investigation.

The need for prosthodontic rehabilitation is high in young adults with PWS. Three study participants $(M / 24$, $\mathrm{M} / 27, \mathrm{M} / 40$ ) had dental crowns on all their teeth at examination as a result of extreme tooth wear. Following the examination, four others $(\mathrm{M} / 23, \mathrm{~F} / 24, \mathrm{M} / 28, \mathrm{M} / 36)$ required referral to a prosthodontist to have all teeth treated with dental crowns. This means that seven of 26 adults in the study group (27\%) had all their teeth crowned between the age of 22 and 36 years. One adult study participant needed endodontic treatment prior to prosthodontic treatment due to pulp exposure in 6 teeth. He had never complained of pain or sensitivity to cold or heat. High pain threshold in individuals with PWS is recognized [68,69] and should be taken into account in the examination and treatment of individuals with PWS. Tooth wear is a multifactorial injury and the cause may vary between individuals. Despite the limitations of the present study due to its study design, the results highlight the strength of association between possible causative factors and tooth wear in PWS. Preventive treatment is important in this group. Dental splints, for example, may be useful for some, although they may be poorly-tolerated by others. Reducing dietary consumption of acid and replacing soft drinks with water may also protect against tooth wear. Tooth wear should be closely monitored by the dental team to facilitate early diagnosis. Regular follow up is necessary to assess the need for timely restorative treatment.

\section{Conclusion}

Our study provides evidence that tooth wear, in terms of both erosive wear and attrition, is a significant problem in Prader-Willi syndrome and young adults have a considerable need for prosthodontic rehabilitation.

\section{Competing interests}

The others declare that they have no competing interests.

\section{Authors' contributions}

RS developed the study design and the study protocol in cooperation with $\mathrm{IE}, \mathrm{KS}, \mathrm{LS}$ and HN . She established the primary aims in consultation with the coauthors. RS has been responsible for all data collection and analyses and for ensuring that the results are interpreted and presented correctly. She carried out literature searches and identified relevant literature. RS has written the paper in consultation with the coauthors and takes full responsibility for the content. IE contributed to the conception and design of the study. He assisted with database management and contributed to the analyses of the data. He critically reviewed the paper and approved the final version. KS as the primary supervisor, contributed to the development of the overall study design, its aims and implementation. She critically reviewed the paper and approved the final version. LS assisted in the development of the study design. He supported RS with the statistical analyses and interpretation of the data. He was actively involved in writing the statistical analyses section of the paper. He critically reviewed the paper and approved the final version. $\mathrm{HN}$ contributed to the development of the study design and the aims of this paper. She also contributed to the analyses and to the interpretation of saliva data. She critically reviewed the paper and approved the final version.

\section{Authors' information}

$\mathrm{RS}, \mathrm{HN}$ and KS work at the National Resource Centre where patients with rare conditions $(<1: 10000)$ are referred from the whole country. With the support of our specialists we collect, systematize and disseminate knowledge about oral health problems in rare conditions. We examine patients, suggest treatment plans, teach students and give courses. Research is an important part of our activities.

\section{Acknowledgements}

The authors thank the Norwegian Prader-Willi syndrome association, all those who participated in the study and their families and all our co-operators at the Faculty of Dentistry, University of Oslo. This study was supported by a grant from the Norwegian Foundation of Health and Rehabilitation, through the Norwegian Prader-Willi syndrome association.

\section{Author details}

${ }^{1}$ TAKO-centre, Lovisenberg Diakonale Hospital, Lovisenberggt 17, 0440 Oslo, Norway. ${ }^{2}$ Faculty of Dentistry, University of Oslo, Oslo, Norway.

Received: 16 September 2011 Accepted: 18 April 2012

Published: 28 May 2012

\section{References}

1. Whittington JE, Holland AJ, Webb T, Butler J, Clarke D, Boer H: Population prevalence and estimated birth incidence and mortality rate for people with Prader-Willi syndrome in one UK Health Region. J Med Genet 2001, 38:792-798.

2. Smith A, Egan J, Ridley G, Haan E, Montgomery P, Williams K, Elliott E: Birth prevalence of Prader-Willi syndrome in Australia. Arch Dis Child 2003, 88:263-264.

3. Vogels A, Van Den Ende J, Keymolen K, Mortier G, Devriendt K, Legius E, Fryns JP: Minimum prevalence, birth incidence and cause of death for Prader-Willi syndrome in Flanders. Eur J Hum Genet 2004, 12:238-240.

4. Thomson AK, Glasson EJ, Bittles AH: A long-term population-based clinical and morbidity review of Prader-Willi syndrome in Western Australia. $J$ Intellect Disabil Res 2006, 50:69-78.

5. Burd L, Vesely B, Martsolf J, Kerbeshian J: Prevalence study of Prader-Willi syndrome in North Dakota. Am J Med Genet 1990, 37:97-99.

6. Akefeldt A, Gillberg C, Larsson C: Prader-Willi syndrome in a Swedish rural county: epidemiological aspects. Dev Med Child Neurol 1991, 33:715-721.

7. Cassidy SB, Forsythe M, Heeger S, Nicholls RD, Schork N, Benn P, Schwartz S: Comparison of phenotype between patients with Prader-Willi syndrome due to deletion 15q and uniparental disomy 15. Am J Med Genet 1997, 68:433-440.

8. Prader A, Labhart A, Willi H: Ein syndrom von adipositas, Kleinwuchs, Kryptorchismus, und Oligophrenie nach myotonieartigem Zustand in Neugeborenenalter. Schweiz Med Wochenschr 1956, 86:1260-1261.

9. Nicholls RD, Knoll JH, Butler MG, Karam S, Lalande M: Genetic imprinting suggested by maternal heterodisomy in nondeletion Prader-Willi syndrome. Nature 1989, 342:281-285.

10. Driscoll DJ, Waters MF, Williams CA, Zori RT, Glenn CC, Avidano KM, Nicholls RD: A DNA methylation imprint, determined by the sex of the parent, distinguishes the Angelman and Prader-Willi syndromes. Genomics 1992, 13:917-924.

11. Nicholls RD: Genomic imprinting and uniparental disomy in Angelman and Prader-Willi syndromes: a review. Am J Med Genet 1993, 46:16-25.

12. Butler MG: Prader-Willi syndrome: current understanding of cause and diagnosis. Am J Med Genet 1990, 35:319-332.

13. Nicholls RD, Knepper $\mathrm{JL}$ : Genome organization, function, and imprinting in Prader-Willi and Angelman syndromes. Annu Rev Genomics Hum Genet 2001, 2:153-175.

14. Holm VA, Cassidy SB, Butler MG, Hanchett JM, Greenswag LR, Whitman BY, Greenberg F: Prader-Willi syndrome: consensus diagnostic criteria. Pediatrics 1993, 91:398-402.

15. Gunay-Aygun M, Schwartz S, Heeger S, O'Riordan MA, Cassidy SB: The changing purpose of Prader-Willi syndrome clinical diagnostic criteria and proposed revised criteria. Pediatrics 2001, 108:E92. 
16. Butler JV, Whittington JE, Holland AJ, Boer H, Clarke D, Webb T: Prevalence of, and risk factors for, physical ill-health in people with Prader-Willi syndrome: a population-based study. Dev Med Child Neurol 2002, 44:248-255.

17. Maas AP, Sinnema M, Didden R, Maaskant MA, Smits MG, SchranderStumpel CT, Curfs LM: Sleep disturbances and behavioural problems in adults with Prader-Willi syndrome. J Intellect Disabil Res 2010, 54:906-917.

18. Yee BJ, Buchanan PR, Mahadev S, Banerjee D, Liu PY, Phillips C, Loughnan G, Steinbeck K, Grunstein RR: Assessment of sleep and breathing in adults with prader-willi syndrome: a case control series. J Clin Sleep Med 2007 3:713-718.

19. Saeves R, Asten P, Storhaug K, Bagesund M: Orofacial dysfunction in individuals with Prader-Willi syndrome assessed with NOT-S. Acta Odontol Scand 2011, 69:310-315.

20. Bray GA, Dahms WT, Swerdloff RS, Fiser RH, Atkinson RL, Carrel RE: The Prader-Willi syndrome: a study of 40 patients and a review of the literature. Medicine (Baltimore) 1983, 62:59-80.

21. Hart PS: Salivary abnormalities in Prader-Willi syndrome. Ann N Y Acad Sci 1998, 842:125-131.

22. Bailleul-Forestier I, Verhaeghe V, Fryns JP, Vinckier F, Declerck D, Vogels A The oro-dental phenotype in Prader-Willi syndrome: a survey of 15 patients. Int J Paediatr Dent 2008, 18:40-47.

23. Stephenson JB: Neonatal presentation of Prader-Willi syndrome. Am J Dis Child 1992, 146:151-152.

24. Saeves R, Nordgarden H, Storhaug K, Sandvik L, Espelid I: Salivary flow rate and oral findings in Prader-Willi syndrome. A case control study. Int J Paediatr Dent 2012, 22:27-36.

25. Bazopoulou-Kyrkanidou E, Papagiannoulis L: Prader-Willi syndrome: report of a case with special emphasis on oral problems. J Clin Pediatr Dent 1992 17:37-40.

26. Salako NO, Ghafouri HM: Oral findings in a child with Prader-Labhart-Willi syndrome. Quintessence Int 1995, 26:339-341.

27. Bots CP, Schueler YT, Brand HS, van Nieuw AA: A patient with Prader-Willi syndrome. Characteristics, oral consequences and treatment options. Ned Tijdschr Tandheelkd 2004, 111:55-58.

28. Scardina GA, Fuca G, Messina P: Oral diseases in a patient affected with Prader-Willi syndrome. Eur J Paediatr Dent 2007, 8:96-99.

29. Anavi Y, Mintz SM: Prader-Labhart-Willi syndrome. Ann Dent 1990, 49:26-29.

30. Bassarelli V, Baccetti T, Bassarelli T, Franchi L: The dentomaxillofacial characteristics of the Prader-Labhart-Willi syndrome. A clinical case report. Minerva Stomatol 1991, 40:811-819.

31. Banks PA, Bradley JC, Smith A: Prader-Willi syndrome-a case report of the multidisciplinary management of the orofacial problems. $\mathrm{Br} J$ Orthod 1996, 23:299-304.

32. Young W, Khan F, Brandt R, Savage N, Razek AA, Huang Q: Syndromes with salivary dysfunction predispose to tooth wear: Case reports of congenital dysfunction of major salivary glands, Prader-Willi, congenital rubella, and Sjogren's syndromes. Oral Surg Oral Med Oral Pathol Oral Radiol Endod 2001, 92:38-48.

33. Mulic A, Tveit AB, Wang NJ, Hove LH, Espelid I, Skaare AB: Reliability of two clinical scoring systems for dental erosive wear. Caries Res 2010, 44:294-299

34. Ekfeldt A, Hugoson A, Bergendal T, Helkimo M: An individual tooth wear index and an analysis of factors correlated to incisal and occlusal wear in an adult Swedish population. Acta Odontol Scand 1990, 48:343-349.

35. Lussi A: Dental erosion clinical diagnosis and case history taking. Eur $J$ Oral Sci 1996, 104:191-198.

36. Bulman JS, Osborn JF: Statistics in dentistry. London: British Dental Journal; 1989.

37. Cole TJ, Bellizzi MC, Flegal KM, Dietz WH: Establishing a standard definition for child overweight and obesity worldwide: international survey. BMJ 2000, 320:1240-1243.

38. Bardsley PF: The evolution of tooth wear indices. Clin Oral Investig 2008, 12 (Suppl 1):S15-S19.

39. Lussi A, Schaffner M, Hotz P, Suter P: Dental erosion in a population of Swiss adults. Community Dent Oral Epidemiol 1991, 19:286-290.

40. Arnadottir IB, Saemundsson SR, Holbrook WP: Dental erosion in Icelandic teenagers in relation to dietary and lifestyle factors. Acta Odontol Scand 2003, 61:25-28.

41. Dugmore CR, Rock WP: A multifactorial analysis of factors associated with dental erosion. Br Dent J 2004, 196:283-286.
42. Holbrook WP, Furuholm J, Gudmundsson K, Theodors A, Meurman JH: Gastric reflux is a significant causative factor of tooth erosion. J Dent Res 2009, 88:422-426.

43. Smith BG, Knight JK: An index for measuring the wear of teeth. Br Dent J $1984,156: 435-438$.

44. Ganss C: How valid are current diagnostic criteria for dental erosion? Clin Oral Investig 2008, 12(Suppl 1):S41-S49.

45. Al-Majed I, Maguire A, Murray JJ: Risk factors for dental erosion in 5-6 year old and 12-14 year old boys in Saudi Arabia. Community Dent Ora Epidemiol 2002, 30:38-46.

46. El AH, Bronkhorst EM, Truin GJ: A longitudinal study of tooth erosion in adolescents. J Dent Res 2008, 87:731-735.

47. Larsen MJ, Poulsen S, Hansen I: Erosion of the teeth: prevalence and distribution in a group of Danish school children. Eur J Paediatr Dent 2005, 6:44-47.

48. Holbrook WP, Ganss C: Is diagnosing exposed dentine a suitable tool for grading erosive loss? Clin Oral Investig 2008, 12(Suppl 1):S33-S39.

49. Van't Spijker A, Rodriguez JM, Kreulen CM, Bronkhorst EM, Bartlett DW, Creugers NH: Prevalence of tooth wear in adults. Int J Prosthodont 2009, 22:35-42.

50. Dawes C: Salivary flow patterns and the health of hard and soft oral tissues. J Am Dent Assoc 2008, 139(Suppl):18S-24S.

51. Akefeldt $A$ : Water intake and risk of hyponatraemia in Prader-Willi syndrome. J Intellect Disabil Res 2009, 53:521-528.

52. Mahoney EK, Kilpatrick NM: Dental erosion: part 1. Aetiology and prevalence of dental erosion. N Z Dent J 2003, 99:33-41.

53. Millward A, Shaw L, Smith AJ, Rippin JW, Harrington E: The distribution and severity of tooth wear and the relationship between erosion and dietary constituents in a group of children. Int J Paediatr Dent 1994, 4:151-157.

54. Jensdottir T, Arnadottir IB, Thorsdottir I, Bardow A, Gudmundsson K, Theodors A, Holbrook WP: Relationship between dental erosion, soft drink consumption, and gastroesophageal reflux among Icelanders. Clin Oral Investig 2004, 8:91-96.

55. McAllister CJ, Whittington JE, Holland AJ: Development of the eating behaviour in Prader-Willi Syndrome: advances in our understanding. Int J Obes (Lond) 2011, 35:188-197.

56. Khan F, Young WG, Daley TJ: Dental erosion and bruxism. A tooth wear analysis from south east Queensland. Aust Dent J 1998, 43:117-127.

57. Johansson A, Johansson AK, Omar R, Carlsson GE: Rehabilitation of the worn dentition. J Oral Rehabil 2008, 35:548-566.

58. Macaluso GM, Guerra P, Di GG, Boselli M, Parrino L, Terzano MG: Sleep bruxism is a disorder related to periodic arousals during sleep. J Dent Res 1998, 77:565-573.

59. Shetty S, Pitti V, Satish Babu CL, Surendra Kumar GP, Deepthi BC: Bruxism: a literature review. J Indian Prosthodont Soc 2010, 10:141-148.

60. Hertz G, Cataletto M, Feinsilver SH, Angulo M: Sleep and breathing patterns in patients with Prader Willi syndrome (PWS): effects of age and gender. Sleep 1993, 16:366-371.

61. Holland AJ, Whittington JE, Butler J, Webb T, Boer H, Clarke D: Behavioural phenotypes associated with specific genetic disorders: evidence from a population-based study of people with Prader-Willi syndrome. Psychol Med 2003, 33:141-153.

62. Bartlett DW, Evans DF, Anggiansah A, Smith BG: A study of the association between gastro-oesophageal reflux and palatal dental erosion. $\mathrm{Br}$ Dent 1996, 181:125-131

63. Munoz JV, Herreros B, Sanchiz V, Amoros C, Hernandez V, Pascual I, Mora F, Minguez M, Bagan JV, Benages A: Dental and periodontal lesions in patients with gastro-oesophageal reflux disease. Dig Liver Dis 2003, 35:461-467.

64. Pace F, Pallotta S, Tonini M, Vakil N, Bianchi PG: Systematic review: gastrooesophageal reflux disease and dental lesions. Aliment Pharmacol Ther 2008, 27:1179-1186.

65. Valipour A, Makker HK, Hardy R, Emegbo S, Toma T, Spiro SG: Symptomatic gastroesophageal reflux in subjects with a breathing sleep disorder. Chest 2002, 121:1748-1753.

66. Green BT, Broughton WA, O'Connor JB: Marked improvement in nocturnal gastroesophageal reflux in a large cohort of patients with obstructive sleep apnea treated with continuous positive airway pressure. Arch Intern Med 2003, 163:41-45.

67. Friedenberg FK, Xanthopoulos M, Foster GD, Richter JE: The association between gastroesophageal reflux disease and obesity. Am J Gastroenterol 2008, 103:2111-2122. 
68. Brandt BR, Rosen I: Impaired peripheral somatosensory function in children with Prader-Willi syndrome. Neuropediatrics 1998, 29:124-126.

69. Priano L, Miscio G, Grugni G, Milano E, Baudo S, Sellitti L, Picconi R, Mauro A: On the origin of sensory impairment and altered pain perception in Prader-Willi syndrome: a neurophysiological study. Eur J Pain 2009, 13:829-835.

doi:10.1186/1472-6831-12-12

Cite this article as: Saeves et al.: Severe tooth wear in Prader-Willi syndrome. A case-control study. BMC Oral Health 2012 12:12.

\section{Submit your next manuscript to BioMed Central} and take full advantage of:

- Convenient online submission

- Thorough peer review

- No space constraints or color figure charges

- Immediate publication on acceptance

- Inclusion in PubMed, CAS, Scopus and Google Scholar

- Research which is freely available for redistribution 